\title{
Erratum to: The Lifelong Impact of Childhood Parental Loss: Manifestations and Management
}

\author{
Salman Akhtar
}

\section{Erratum to:}

Chapter 12 in: S. Malhotra and P. Santosh (eds.),

Child and Adolescent Psychiatry, https://doi.org/10.1007/978-81-322-3619-1_12

In the original version of the book, the text "This chapter was originally published in Matters of Life and Death: Psychoanalytic Reflections by Salman Akhtar (published by Karnac Books in 2011), and is reprinted with kind permission of Karnac Books." has been included in the opening page of Chapter 12 as article note.

The updated online version of this chapter can be found at https://doi.org/10.1007/978-81-322-3619-1_12 